\title{
Should courts decide on euthanasia?
}

By making a sick and malformed child a ward of court, three British judges have drawn attention to the need for a judicial procedure in cases where sick people seek euthanasia voluntarily.

EUTHANASIA is a perpetually haunting issue that usually arises in relation to the elderly sick or adults who are terminally ill. The argument that people in such a plight should be enabled by their physicians to die is a powerful one, at least when the demand is a voluntary decision of the person concerned, and when there are medical grounds for believing that he or she is in any case nearing death. Why needlessly prolong suffering? The difficulty, for the supporters of voluntary euthanasia, is that the counter-arguments are also strong - stronger than the euthanasia lobby (every country has one) acknowledges. Knowing whether an expression of a wish to be allowed to die is strictly voluntary is one difficulty; telling the difference between a wish to die and a wish not to be a nuisance to others can never be simple, for example. And (pace current practice in The Netherlands) there is force in the argument that legitimizing physicianassisted suicide would be a dangerous precedent and invidious for physicians.

Now the British courts have been thrust into a situation of this kind, and have responded in an enlightened fashion that may point the way to a more generally accepted policy on euthanasia. The case on which three Law Lords adjudicated last week concerns a child born more than a year ago with severe malformations. The extent of the brain damage (suffered in utero) is apparently so great that the child will never be mentally competent. Although not dependent on an incubator for survival, the child must be fed through a tube inserted into its stomach. Its time is divided between a hospital and its parents' house, who care for it. The parents had applied to the courts for the termination of the child's life, presumably by starvation.

This is not a case of voluntary euthanasia, of course; the child has no say in the matter. The case for ending the child's life is partly to lift the burden of distress and care imposed on the parents and, less cogently, partly because the child has no future as a person. Religious people will strongly object on both grounds, and their objections cannot be lightly brushed aside. Freedom from distress is not an absolute right, but is (or at least can be) ennobling. And who is to say that a person whose IQ is not measurable is not a person? A more immediate difficulty for the courts would be that granting this application would presumably stimulate a flood of similar applications by the relatives of elderly and incompetent persons. So what did the court decide? Make the child a "ward of court", which is a procedure in which the responsibilities of parenthood pass to the legal system. In this case, the child will continue to live with its parents and in their local hospital. The court has said that it will hear further argument from the parents when they have more to say.

That decision is enlightened because it makes a decision about life or death a judicial process, which is right and proper. Why should not the same procedures be followed in cases of voluntary euthanasia? Then it would be possible to test by taking evidence whether a person's expressed wish to die is strictly voluntary and also to ensure that the medical circumstances of the case are generally agreed. Distressing though they would be, cases of this kind should be heard in public, for death (like birth) should be a matter of the public record. But the chief benefit of such a development is that it would rid physicians faced with demands to be helped to die of a responsibility that should not be shouldered individually.

\section{Privatization goes wrong}

Britain, with a recent rich record of denationalization, has error as well as success to boast of.

Not for nothing has the British government been boasting over the past decade that its programme of selling off nationalized industries to would-be private owners has been widely emulated elsewhere in the world. Governments of all stripes have followed suit. Not only the free-market economies of Western Europe, but the states of Central Europe and the ex-Soviet Union, have joined in the public auction of what were previously assets of the state. The Russian government in the past two years has surprised its voters and even itself by the speed and the degree to which it has turned over the ownership of state industry to the general public.

In all cases, the motives behind the drive for privatization appear to be similar. Governments have discovered that the means by which politicians and civil servants are recruited to the public service do not ensure their aptitude as industrial managers, that it is often a waste of financial resources that public capital should be locked up in enterprises that private persons would be willing to own and that there are intolerable conflicts between the interests of nationalized industries (especially when they are in trouble) and the public interest generally. For all those reasons, the fashion for private 